\title{
Skeletal muscle tissue from the Goto-Kakizaki rat model of type-2 diabetes exhibits increased levels of the small heat shock protein Hsp27
}

\author{
EDEL MULLEN, ELAINE O'REILLY and KAY OHLENDIECK \\ Department of Biology, National University of Ireland, Maynooth, County Kildare, Ireland
}

Received December 6, 2010; Accepted January 20, 2011

DOI: $10.3892 / \mathrm{mmr} .2011 .437$

\begin{abstract}
In order to increase our understanding of diabetes-related muscle weakness, we carried out a mass spectrometry-based proteomic analysis of skeletal muscle preparations from the Goto-Kakizaki rat model of type-2 diabetes. Fluorescence difference in-gel electrophoresis was performed to determine potential differences in the global protein expression profile of muscle extracts. Besides changes in contractile proteins and metabolic enzymes, the abundance of the small stress proteins $\alpha \mathrm{B}$-crystallin and Hsp27 was significantly increased. The up-regulation of the lowmolecular-mass heat shock protein Hsp27 was confirmed by an alternative fluorescent staining method of two-dimensional gels and immunoblotting. The observed protein alterations in the cellular stress response, distinct metabolic pathways, regulatory mechanisms and the contractile apparatus might be directly or indirectly associated with peripheral resistance to insulin signalling, making these newly identified muscle proteins potential biomarkers of type- 2 diabetes. Increased levels of molecular chaperones suggest considerably enhanced cellular stress levels in diabetic muscle fibres.
\end{abstract}

\section{Introduction}

The application of gel electrophoresis-based proteomics in diabetes research is a fast growing field (1), including the proteomic analysis of diabetic skeletal muscle tissues (2-7). Since diabetes is increasingly prevalent in the general

Correspondence to: Professor Kay Ohlendieck, Department of Biology, National University of Ireland, Maynooth, Co. Kildare, Ireland

E-mail: kay.ohlendieck@nuim.ie

Abbreviations: DIGE, difference in-gel electrophoresis; GK, GotoKakizaki; Hsp, heat shock protein; MS, mass spectrometry; RuBPs, ruthenium bathophenanthroline disulfonate

Key words: difference in-gel electrophoresis, Goto-Kakizaki rat, Hsp27, muscle proteomics, type-2 diabetes population, research into the complex pathophysiological mechanisms that underlie abnormal signaling in crucial target organs, such as skeletal muscle, is of central importance (8-10). It is now clear that type- 2 diabetes mellitus represents a group of heterogeneous disorders with abnormal expression patterns in various genes and protein products (11-13). Peripheral insulin resistance in the liver, adipose tissue and muscles, as well as impaired pancreatic $\beta$-cell functioning, are the principal features of type- 2 diabetes (11). The worldwide incidence of type-2 diabetes is dramatically increasing (14) and it has been estimated that the incidence of diabetes will rise to a staggering $4.4 \%$ by the year 2030, with 366 million affected patients (15). Importantly, type- 2 diabetes is associated with a loss of skeletal muscle mass and contractile strength (16-19) warranting detailed investigations into diabetes-related muscle weakness (20). In this respect, large-scale biochemical approaches, such as gel electrophoresis-based proteomics, are ideal analytical tools for an unbiased identification of novel protein factors that are associated with abnormal functioning in diabetic fibres.

High-resolution two-dimensional gel electrophoresis has long been established as one of the most powerful biochemical techniques for the comparative analysis of large protein complements (21-23). The more recent combination of advanced gel electrophoretic methods with mass spectrometry has further reinforced the central importance of gel electrophoretic techniques for analytical protein chemistry (24-26). The unprecedented advancements of mass spectrometric methods for the swift identification of minute amounts of protein (27) and the emergence of high-throughput proteomics as a major new field in modern biochemistry (28) have opened unparalleled opportunities for the in-depth analysis of complex pathological processes. However, a major obstacle for the inclusive cataloging of large and diverse protein complements is the dynamic concentration range of protein species within a given class of cells or tissues. Since different staining techniques used in two-dimensional gel electrophoresis visualize varied dynamic expression ranges, protein labeling may considerably influence proteomic identification protocols. Here, we have used fluorescence difference in-gel electrophoresis (DIGE) for the determination of potential expression changes in the soluble proteome from normal Wistar rat muscle versus type-2 diabetic Goto-Kakizaki (GK) rat muscle. The GK rat is an 
established animal model of non-obese type-2 diabetes (29) that exhibits peripheral insulin resistance (30) and numerous molecular and cellular abnormalities due to its diabetic status (30-32), including abnormal skeletal muscle functions (33-38).

Our comparative mass spectrometry-based proteomic analysis revealed a moderately disturbed protein expression pattern in diabetic muscle fibres. Mass spectrometry identified 15 distinct two-dimensional protein spots with an altered abundance in diabetic muscle tissue preparations, using analytical DIGE gels with a $\mathrm{pH}$ 3-10 range. Besides altered expression patterns in various contractile and metabolic muscle proteins, a striking increase in two heat shock proteins (Hsp), $\alpha$ B-crystallin and Hsp27, was established by densitometric scanning and mass spectrometry. Muscle-associated Hsps protect contractile fibres during hyperthermia, hypoxic insult, ischemic damage, extensive periods of exercise, traumatic injury and in numerous neuromuscular diseases (39). Hsps of low molecular mass are specifically induced during muscle injury (40), whereby their main cytoprotective functions include the prevention of deleterious protein aggregation and the modulation of intermediate filament assembly (41). Small Hsps are characterized by a conserved 90-residue carboxy-terminal sequence, the $\alpha$-crystallin domain (42). The abundance of these small cytoprotective chaperones appears to be increased in GK muscle tissue. Hence, diabetesrelated changes in the cellular stress response, the contractile machinery, metabolic pathways and various regulatory mechanisms are possibly linked to peripheral insulin resistance in skeletal muscles. In the future, these novel signature molecules might be helpful for the establishment of a comprehensive biomarker signature of type- 2 diabetes mellitus.

\section{Materials and methods}

Materials. Electrophoretic buffers, protein assay reagents and protein molecular weight ladders were obtained from Bio-Rad Laboratories (Hemel Hempstead, Hertfordshire, UK). Ultrapure Protogel acrylamide stock solutions and nitrocellulose membranes were from National Diagnostics (Atlanta, GA, USA) and Millipore (Bedford, MA, USA), respectively. Fluorescent CyDyes, imobiline $\mathrm{pH}$ gradient IPG dry strips, ampholytes, cover fluid and acetonitrile were purchased from Amersham Bioscience/GE Healthcare (Little Chalfont, Bucks, UK). Sequencing grade-modified trypsin, used for the peptide mass spectrometric identification of skeletal muscle proteins, was obtained from Promega (Madison, WI, USA). LC-MS Chromasolv water and formic acid were purchased from Fluka (Milwaukee, WI, USA). Coomassie Brilliant Blue G-250 dye was from Thermo Fisher Scientific (Waltham, MA, USA). Primary antibodies were obtained from Abcam Ltd. (Cambridge, UK) (ab12351 to Hsp27; ab36329 to isocitrate dehydrogenase; ab88184 to myozenin; ab16834 to superoxide dismutase; ab89511 to actin capping-protein; and ab54913 to carbonic anhydrase CA3). Secondary peroxidase-conjugated antibodies were purchased from Chemicon International (Temecula, CA, USA). Protease inhibitors and chemiluminescence blotting substrate were obtained from Roche Diagnostics (Mannheim, Germany). All other analytical-grade chemicals were purchased from Sigma Chemical Company (Dorset, UK).
Diabetic animal model. For the comparative proteomic analysis of normal versus diabetic muscle tissue, normal Wistar rats and the spontaneous diabetic Goto-Kakizaki (GK) rat were used in this study. The GK rat is an established model of non-obese type-2 diabetes (29-32). Rats were purchased from Taconic M\&B Ltd. Animal Suppliers (Ry, Denmark). The total soluble proteome was extracted from the gastrocnemius muscles of 9-week-old normal rats and age-matched GK rats. The diabetic status of the cohort of GK rats employed in this study has previously been described in detail (37).

Preparation of muscle extract. Gastrocnemius muscle samples from normal and GK rats with a wet weight of $200 \mathrm{mg}$ were quick-frozen in liquid nitrogen and then ground into a fine powder using a mortar and pestle. The muscle powder was transferred into $1 \mathrm{ml}$ lysis buffer containing $2 \%$ (v/v) pH 3-10 ampholytes, $7 \mathrm{M}$ urea, $2 \mathrm{M}$ thiourea, 4\% (w/v) CHAPS and $100 \mathrm{mM}$ dithiothreitol. A freshly prepared protease inhibitor cocktail was added to the buffer to prevent proteolytic degradation of sensitive muscle proteins (5). The suspension was incubated for $3 \mathrm{~h}$ at room temperature and then centrifuged at $14,000 \mathrm{x} \mathrm{g}$ for $20 \mathrm{~min}$ at $4^{\circ} \mathrm{C}$. The Bradford dye-binding method was used to determine the protein concentration of the final extracts from normal versus GK muscle tissue (43).

Gel electrophoretic analysis. Total crude skeletal muscle extracts of normal $(n=4)$ and diabetic $(n=4)$ muscle tissues were separated in the first dimension by isoelectric focusing and in the second dimensional by standard sodium dodecyl sulphate polyacrylamide gel electrophoresis, as previously described by our laboratory (44-46). IPG strips were rehydrated for $12 \mathrm{~h}$ in a buffer consisting of $7 \mathrm{M}$ urea, $2 \mathrm{M}$ thiourea, $4 \%(\mathrm{w} / \mathrm{v})$ CHAPS, $1.2 \%$ deStreak and 2\% (v/v) pH 3-10 ampholytes. The buffer system contained $400 \mu \mathrm{g}$ of muscle protein. The first-dimension protein separation was conducted using IPG strips on an Amersham IPGphor IEF system (Amersham Bioscience/GE Healthcare) following the protocol previously described in detail (44). The first dimension strips were further subjected to reduction and alkylation (45) before separation in the second-dimension on $12.5 \%(\mathrm{w} / \mathrm{v})$ slab gels using an Amersham Ettan DALT-Twelve system (46).

Protein visualisation. For DIGE analysis, Cy3 and Cy5 dyes were reconstituted as a stock solution of $1 \mathrm{mM}$ in fresh dimethylformamide. The stock solution was diluted to a working solution of $0.2 \mathrm{mM}$ prior to protein labelling. Individual samples (50 $\mu \mathrm{g}$ protein) were minimally labelled with 200 pmols of $\mathrm{Cy} 3$ working solution (47). A pooled sample consisting of equal quantities of protein from all replicates used in the experiment were labelled at a ratio of 200 pmol of Cy5 working solution to $50 \mu \mathrm{g}$ of muscle protein. All samples were labelled with the appropriate amount of dye at $\mathrm{pH} 8.5$ and then incubated on ice in the dark for $30 \mathrm{~min}$. The reaction was quenched by $10 \mathrm{mM}$ lysine for $10 \mathrm{~min}$ on ice in the dark. During the subsequent rehydration step, samples were loaded onto IPG strips with an equal volume of 2X sample buffer (7 M urea, $2 \mathrm{M}$ thiourea, $65 \mathrm{mM}$ CHAPS, $2 \%$ ampholytes and $2 \%$ dithiothreitol). Slab gels were stained for total protein with Coomassie Brilliant Blue or ruthenium bathophenanthroline disulfonate (RuBPs). A stock solution 
of RuBPs dye was prepared as described by Rabilloud et al. (48). Two-dimensional gels were fixed overnight in $30 \%(\mathrm{v} / \mathrm{v})$ ethanol and $10 \%(\mathrm{v} / \mathrm{v})$ acetic acid and subsequently washed 4 times for $30 \mathrm{~min}$ in $20 \%(\mathrm{v} / \mathrm{v})$ ethanol to remove traces of acetic acid (49). The ruthenium fluorophore was then applied to the gels by adding $10 \mathrm{ml}$ of the freshly synthesized dye to 1 litre of $20 \%$ (v/v) ethanol in the dark. Gels were incubated for $6 \mathrm{~h}$ in the staining solution. Labelled gels were then destained in $40 \%$ (v/v) ethanol and $10 \%$ (v/v) acetic acid. Reference gels for spot picking were stained with Coomassie Brilliant Blue (46). Gel images were analysed using Progenesis SameSpots software version 3.2.3 from NonLinear Dynamics (Newcastle upon Tyne, UK).

Mass spectrometric identification of skeletal muscle proteins. The mass spectrometric analysis of peptide mixtures derived from distinct two-dimensional spots was carried out on a Model 6430 Ion Trap LC/MS apparatus from Agilent Technologies (Santa Clara, CA, USA). The excision of protein spots and subsequent washing, destaining and digestion steps were preformed by a previously optimised method (44-46). Trypsination-generated peptides were recovered from supernatants of digested gel plugs and samples dried through vacuum centrifugation. The resulting peptides were resuspended in $10 \mu \mathrm{l}$ of $\mathrm{MS}$-grade $\mathrm{ddH}_{2} \mathrm{O}$ and $0.1 \%$ (w/v) formic acid for identification by ion trap LC-MS analysis. Separation of peptides was performed with a nano flow Agilent 1200 series system, equipped with a Zorbax 300SB-C $185 \mathrm{~mm}$, $4 \mathrm{~mm} 40 \mathrm{nl}$ pre-column and a Zorbax 300SB-C $185 \mathrm{~mm}$, $43 \mathrm{~mm} \times 75 \mu \mathrm{m}$ analytical reversed- phase column using HPLC-Chip technology (50). Mobile phases utilized were A, $0.1 \%$ formic acid; B, $50 \%$ acetonitrile and $0.1 \%$ formic acid. Samples $(5 \mu \mathrm{l})$ were loaded into the enrichment at a capillary flow rate set to $2 \mu \mathrm{l} / \mathrm{min}$ with a mix of $\mathrm{A}$ and $\mathrm{B}$ at a ratio of 19:1. Tryptic peptides were eluted with a linear gradient of $10-90 \%$ solvent B over $2 \mu \mathrm{l} / \mathrm{min}$ with a constant nano pump flow of $0.6 \mathrm{ml} / \mathrm{min}$. A $1 \mathrm{~min}$ post time of solvent A was used to remove sample carry over. The capillary voltage was set to $1700 \mathrm{~V}$. The flow and the temperature of the drying gas were $4 \mu \mathrm{l} / \mathrm{min}$ and $300^{\circ} \mathrm{C}$, respectively (5). Database searches were carried out with Spectrum Mill Work Bench or Mascot MS/ MS Ion search (Matrix Science, London, UK).

Immunoblot analysis. To verify changes in the abundance of select proteins in GK muscle preparations, immunoblotting was carried as previously described in detail (37). Gels were transferred to nitrocellulose and blocked with a milk protein solution consisting of $5 \%(\mathrm{w} / \mathrm{v})$ fat-free milk powder in $0.9 \%(\mathrm{w} / \mathrm{v}) \mathrm{NaCl}, 50 \mathrm{mM}$ sodium phosphate, $\mathrm{pH} 7.4$ for $1 \mathrm{~h}$. Subsequently, membranes were incubated overnight with sufficiently diluted primary antibody, washed and then incubated for $1 \mathrm{~h}$ with secondary peroxidase-conjugated antibodies, diluted in blocking solution. The visualization of immuno-decorated bands was carried out by the enhanced chemiluminescence method using blotting substrate from Roche Diagnostics (Mannheim, Germany). Densitometric scanning of immunoblots was performed on a Molecular Dynamics 300S computing densitometer (Sunnyvale, CA, USA) with ImageJ (NIH, USA) and GraphPad Prism (San Diego, CA, USA) software.

\section{Results}

Proteomic analysis of diabetic GK muscle extracts. Difference in-gel electrophoresis (DIGE) represents an excellent analytical tool for large-scale proteomic surveys (51-53), and this method was applied here for the comparative analysis of normal versus diabetic muscle extracts. With the help of a Typhoon Trio variable imager and Progenesis 2-D analysis software, 15 protein species out of 1734 detectable two-dimensional spots were found to be differentially expressed. Representative Cy3 and Cy5 gels with electrophoretically separated proteins from normal versus diabetic muscle tissue are shown for the $\mathrm{pH}$ 3-10 range in Fig. 1A-D. The protein spot patterns of normal versus pathological preparations were relatively comparable. However, the detailed densitometric analysis of Wistar rat versus GK rat muscle tissue identified distinct changes in a variety of protein species. A representative DIGE master gel of GK rat skeletal muscle preparations employed for the mass spectrometric identification of proteins with a diabetes-related differential expression pattern is shown in Fig. 1E. Skeletal muscle proteins that exhibited a more than 2-fold change in expression levels are marked by circles and are numbered 1 to 15 . Proteins species with a changed concentration in GK gastrocnemius muscle ranged in molecular mass from $16 \mathrm{kDa}$ (hemoglobin) to $224 \mathrm{kDa}$ (myosin heavy chain) and covered a $\mathrm{p} I$-range from $\mathrm{p} I 4.1$ (troponin) to $\mathrm{p} I 8.9$ (bisphosphoglycerate mutase). An increased abundance was found in the case of 10 skeletal muscle-associated proteins, and 5 proteins were shown to be decreased in their concentration.

Proteomic profile of diabetic skeletal muscle tissue. A list of the 15 DIGE-identified muscle proteins that exhibited a drastically altered expression level in the non-obese diabetic GK rat is shown in Table I. Listed are the names of the identified proteins, their international protein accession number, $\mathrm{p} I$-values, their relative molecular masses, the number of matched peptide sequences, percentage sequence coverage, Mascot scores, and fold-change of individual proteins affected in diabetic muscle tissue. The identified muscle proteins were found to be mostly associated with the contractile apparatus, muscle metabolism, metabolite transportation and the cellular stress response. The numbering of spots in the DIGE-labeled master gel of Fig. 1E correlates with the listing of mass spectrometry-identified protein species in Table I. The protein with the highest decrease in concentration was identified as bisphosphoglycerate mutase, and that with the highest increase in abundance shown to be the fast 1f-isoform of myosin light chain. Muscle proteins with a drastic decrease were found to be bisphosphoglycerate mutase (spot 1), myosin heavy chain 4 (spot 2), troponin C (spot 3), Tip1 protein (spot 4) and hemoglobin (spot 5). In contrast, muscle proteins with an increased expression in diabetic muscle tissue were identified as fast troponin T (spots 6 and 11), tropomyosin (spot 7), slow myosin light chain 3 (spot 8), fast myosin light chain 1f (spots 9 and 15), Hsp27 (spot 10), $\alpha \mathrm{B}$-crystallin (spot 12), myozenin (spot 13) and myoglobin (spot 14).

RuBPs analysis of Hsp27 in GK muscle extracts. To verify the increased levels of the low-molecular-mass molecular chaperone Hsp27 in GK muscle, as revealed by DIGE analysis, the 

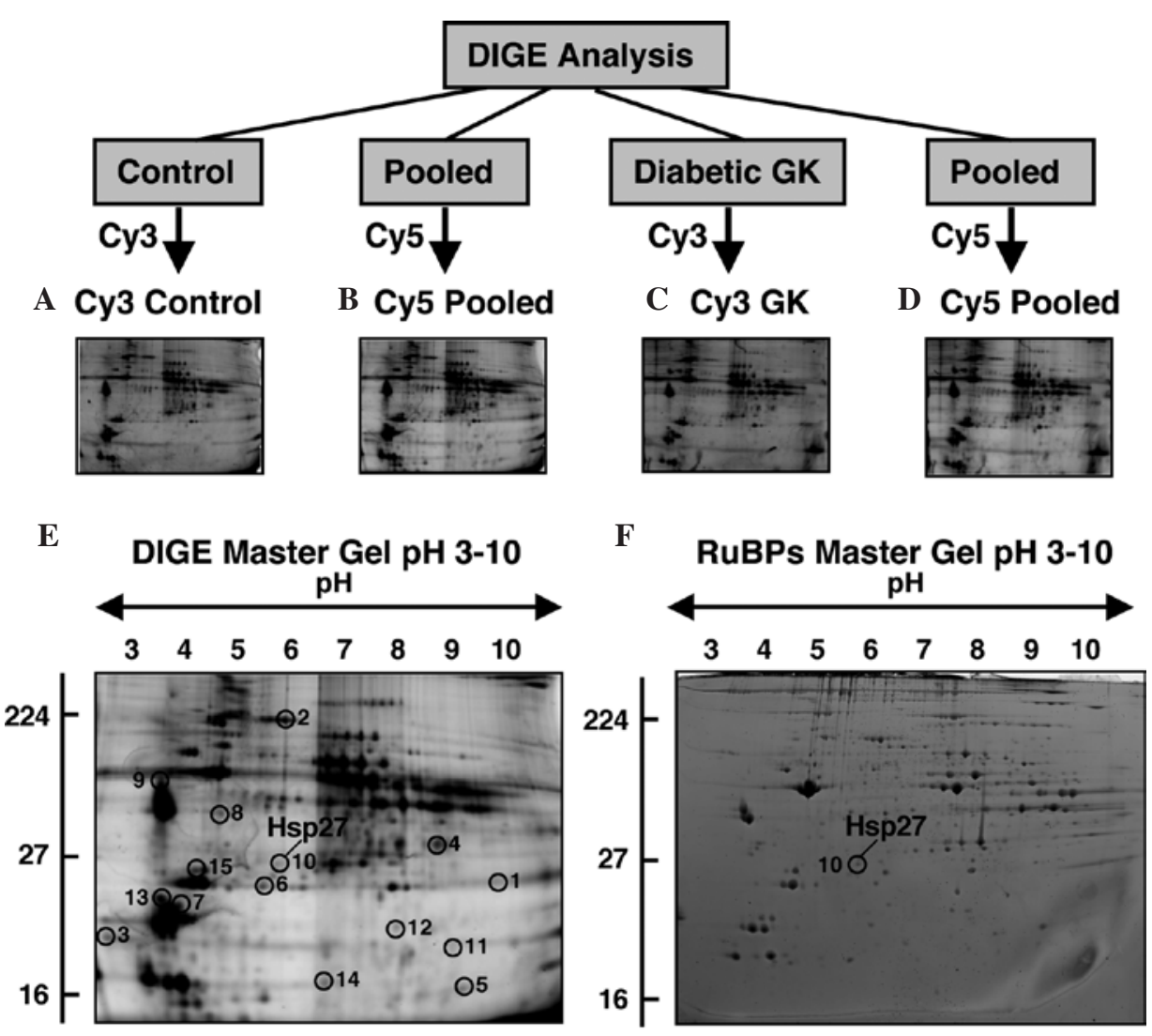

\begin{tabular}{|c|c|c|c|}
\hline G & $\begin{array}{l}\text { Mass spectrometric finger } \\
\text { protein Hsp27 from rat ske }\end{array}$ & $\begin{array}{l}\text { int of small } r \\
\text { tal muscle - }\end{array}$ & $\begin{array}{l}\text { at shock } \\
\text { il1170367। }\end{array}$ \\
\hline 1 & pfsl lrspswepfr & dwypahsrlf & dqafgvprfp \\
\hline 41 & dewsqwfssa gwpgyvrplp & $\overline{\text { aataegpaav }}$ & tlarpfsral \\
\hline 81 & nrqlssgvse irqtadrwrv & sldvnhfape & eltvktkegv \\
\hline 121 & veitgkheer qdehgyisrc & ftrkytlppg & vdptlvsssl \\
\hline 161 & spegtltvea plpkavtqsa & eitipvtfea & raqiggpese \\
\hline 201 & qsgak & & \\
\hline
\end{tabular}

Figure 1. Proteomic profiling of diabetic rat GK skeletal muscle using fluorescent DIGE analysis and RuBPs staining. Crude total muscle extracts from normal and Goto-Kakizaki (GK) gastrocnemius muscle tissue were separated in the first dimension by isolelectric focusing and in the second dimension by sodium dodecyl sulfate polyacrylamide gel electrophoresis. Shown are Cy3-labeled control samples (A), Cy3-labeled diabetic GK samples (C) and Cy5-labeled pooled standards (B, D). A DIGE master gel with a pH 3-10 range is shown in panel (E). Identified muscle proteins are marked by circles and are numbered 1 to 15 . See Table I for a detailed listing of protein species that exhibited a diabetes-related alteration in their expression levels. To verify the changed abundance in the molecular chaperone Hsp27 (spot no. 10), fluorescent RuBPs staining was used (F). The two-dimensioanl spot representing Hsp27 is marked by a circle. The pH-values of the first dimension gel system and molecular mass standards (in $\mathrm{kDa}$ ) of the second dimension are indicated on the top and on the left of panels $(\mathrm{E}, \mathrm{F})$, respectively. The mass spectrometric fingerprint of Hsp27 is shown in panel (G).

fluorescent dye RuBPs was employed for labeling electrophoretically separated muscle proteins. As illustrated in Fig. 1F, a protein spot with an approximate $\mathrm{p} I$-value of 6 and a relative molecular mass of $27 \mathrm{kDa}$ was identified as Hsp27/HspB1. The mass spectrometric fingerprint of the RuBPs-stained Hsp27 protein spot is shown in Fig. 1G and illustrates $60 \%$ coverage of matched peptides. Thus, the densitometric analyses of two independent fluorescent labeling approaches agreed and clearly demonstrated a drastic increase in the small stress protein Hsp27.

Immunoblot analysis of GK muscle extracts. In order to correlate the findings of the DIGE-based study described here and a previously published proteomic survey of GK muscle using Coomassie Brilliant Blue (5), an immunoblot analysis was carried out with normal versus GK preparations. Both the drastic diabetes-related increase in Hsp27 and the actin binding-protein myozenin were clearly confirmed by immunoblotting (Fig. 2A, B and G). The previously established drastic decrease in carbonic anhydrase isoform CA3 and moderate increase in isocitrate dehydrogenase, $\mathrm{Cu} / \mathrm{Zn}$ superoxide dismutase and actin capping-protein were also confirmed (Fig. 2C-F and H). Hence, immunoblotting verified the increased abundance of Hsp27 in diabetic GK muscle tissue and the differential expression pattern of other novel muscle-associated marker proteins of type-2 diabetes. 
Table I. DIGE-identified proteins with a changed abundance in diabetic GK muscle extracts.

\begin{tabular}{|c|c|c|c|c|c|c|c|c|}
\hline $\begin{array}{l}\text { Spot } \\
\text { no. }\end{array}$ & Protein name & $\begin{array}{c}\text { Accession } \\
\text { no. }\end{array}$ & $\begin{array}{l}\text { Iso-electric } \\
\text { point } \mathrm{pI}\end{array}$ & $\begin{array}{l}\text { Molecular } \\
\text { mass (kDa) }\end{array}$ & $\begin{array}{l}\text { Matched } \\
\text { peptides }\end{array}$ & $\begin{array}{c}\text { Coverage } \\
(\%)\end{array}$ & $\begin{array}{c}\text { Mascot } \\
\text { score }\end{array}$ & $\begin{array}{c}\text { Fold } \\
\text { change }\end{array}$ \\
\hline 1 & Bisphospho glycerate mutase & gil83939481 & 8.9 & 28.911 & 16 & 43 & 185 & -3.3 \\
\hline 2 & Myosin heavy chain 4 , skeletal muscle & gil106879208| & 5.6 & 223.669 & 17 & 7 & 181 & -2.4 \\
\hline 3 & Troponin C, type 2 & gil82654194| & 4.1 & 18.142 & 19 & 65 & 482 & -2.2 \\
\hline 4 & Tip1 protein & gil38512111l & 7.1 & 27.228 & 26 & 81 & 459 & -2.1 \\
\hline 5 & $\beta$-hemoglobin & gil204570| & 7.9 & 16.099 & 3 & 28 & 141 & -2.0 \\
\hline 6 & Troponin $\mathrm{T}$, fast & gil136385। & 6.2 & 30.732 & 2 & 11 & 78 & 2.0 \\
\hline 7 & Tropomyosin $2, \beta$ & gil118752031 & 4.7 & 32.933 & 16 & 33 & 361 & 2.1 \\
\hline 8 & Myosin, light chain 3, slow & gil6981240| & 5.0 & 22.258 & 16 & 75 & 288 & 2.1 \\
\hline 9 & Myosin light chain $1 \mathrm{f}$, fast & gil117676401l & 4.9 & 20.782 & 9 & 51 & 113 & 2.1 \\
\hline 10 & Heat shock protein Hsp27 & gil1170367l & 6.1 & 22.937 & 11 & 60 & 119 & 2.4 \\
\hline 11 & Troponin $\mathrm{T}$, fast & gil136385| & 6.2 & 30.732 & 4 & 15 & 86 & 2.4 \\
\hline 12 & $\alpha \mathrm{B}$-crystallin & gil57580| & 8.8 & 19.945 & 13 & 55 & 204 & 2.5 \\
\hline 13 & Myozenin & gil157819165| & 8.6 & 31.379 & 2 & 11 & 109 & 2.6 \\
\hline 14 & Myoglobin & gil11024650| & 7.8 & 17.204 & 2 & 21 & 98 & 3.2 \\
\hline 15 & Myosin light chain $1 \mathrm{f}$, fast & gil117676401l & 4.9 & 20.782 & 6 & 31 & 125 & 3.4 \\
\hline
\end{tabular}
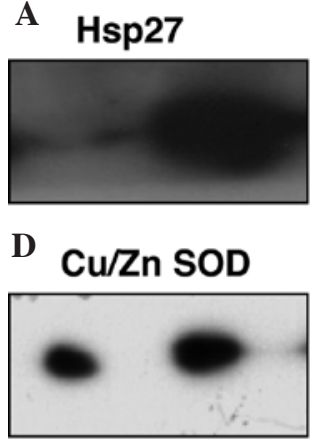

1

G

2

Hsp27

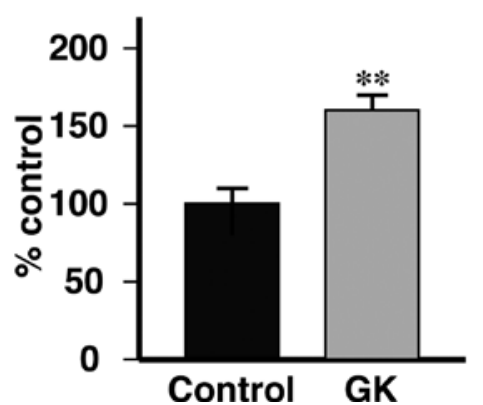

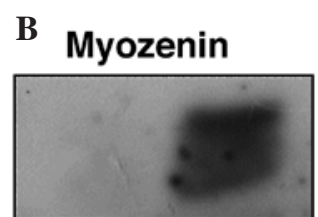

E Actin CP

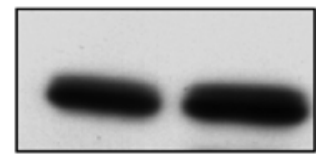

1
C ICDH

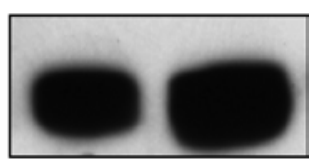

F CA3

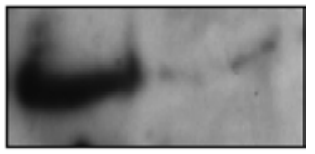

12

H

CA3

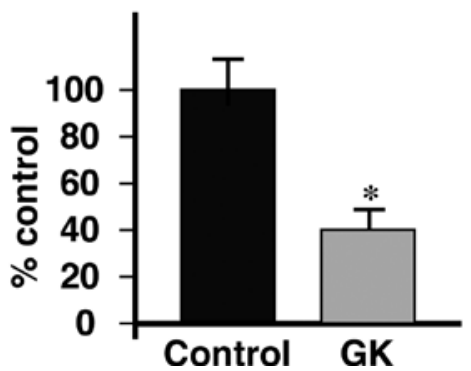

Figure 2. Immunoblot analysis of diabetic rat GK skeletal muscle. Shown are representative immunoblots with expanded views of immuno-decorated bands Immunoblotting was performed with antibodies to the molecular chaperone Hsp27 (A), the actin binding protein myozenin (B), the enzyme isocitrate dehydrogenase $(\mathrm{C}$; ICDH), the enzyme $\mathrm{Cu} / \mathrm{Zn}$ superoxide dismutase (D; SOD), actin capping-protein (E; CP) and the enzyme carbonic anhydrase isoform CA3 (F). Shown is the graphical presentation of the statistical evaluation of immuno-decoration using antibodies to Hsp27 (G) and carbonic anhydrase $\mathrm{CA} 3$ (H). The comparative blotting was statistically evaluated using an unpaired Student's t-test $\left(\mathrm{n}=5 ;{ }^{*} \mathrm{p}<0.05 ;{ }^{* *} \mathrm{p}<0.01\right)$. Lanes 1 and 2 represent normal and diabetic muscle extracts from control and GK rats, respectively.

\section{Discussion}

The GK rat is an established animal model of non-obese type-2 diabetes. Importantly, these animals are spontaneously diabetic (29) and clearly exhibit increased blood glucose levels without significant alterations in non-fasting plasma insulin levels and body weight (30-33). We chose GK muscle tissues because they represent a suitable model system for studying fundamental mechanisms of type-2 diabetes without potentially complicating factors due to obesity. It is important 
to stress that no animal model represents a perfect replica of all pathobiochemical aspects seen in a highly complex human pathology. However, if one keeps in mind speciesspecific differences, findings from animal model proteomics can be extrapolated to the human situation (54). Ideally, a diabetic animal model should closely resemble the etiology of the human disease in onset, progression, complexity and severity, as well as develop all or most of the multi-factorial aspects usually observed in end-stage human pathology. A good model system should also mimic the basic mechanisms of human physiology and metabolism that are important for the development of diabetic side effects. It is therefore critical to choose the right age range of pathological GK tissues to study diabetic dysfunctions at a prominent stage of disease progression. It was previously reported that cellular defects in insulin secretion and peripheral insulin resistance occur by 4 weeks of age in the GK rat $(30,31)$. The proteomic profiling of diabetic muscle described here was therefore performed with 9-week-old animals that clearly exhibited elevated levels of glucose (37).

Diabetic GK skeletal muscles are characterized by an inhibition of insulin receptor auto-phosphorylation (33), impaired activities of numerous key insulin signaling intermediates (32-34), a diminished recruitment of glucose transporter GLUT4 molecules possibly linked to membrane cytoskeletal defects in the dystrophin-dystroglycan complex $(20,37)$, drastically lowered mitochondrial enzyme activities (38) and a reduced percentage of oxidative fibres (35). These findings demonstrate chronically impaired insulin signaling in GK skeletal muscles making them a suitable model system to determine global changes in the protein expression pattern due to diabetic complications. The proteomic analysis presented here has clearly shown increased levels of the small chaperone Hsp27, also termed HspB1 (42), in GK muscle preparations. Importantly, results of our DIGE analysis were confirmed by fluorescence RuBPs labeling and immunoblotting. This report therefore confirms the findings of a previous proteomic characterization of GK muscle using Coomassie Brilliant Blue staining (5) and suggests a considerable up-regulation of specific low-molecular-mass chaperones in diabetic muscle tissue. The main cytoprotective functions of small Hsps include the modulation of intermediate filament assembly and the prevention of deleterious protein aggregation (41). In addition, increased levels of $\mathrm{Cu}-\mathrm{Zn}$ superoxide dismutase (55) suggest a critical need of diabetic muscles for an up-regulation of the anti-oxidant defense system. Thus, in analogy to dystrophic and aged skeletal muscles $(45,56)$, contractile tissue seems to be associated with considerable levels of cellular stress due to type-2 diabetes.

In addition, the proteomic screening of GK muscle tissue also revealed protein alterations in the contractile apparatus and metabolic elements, suggesting a generally perturbed protein expression patterns due to diabetic side effects. These diabetes-related changes might be directly or indirectly associated with peripheral insulin resistance. The status of these newly identified markers of type- 2 diabetes needs to be verified by detailed biochemical, physiological and cell biological characterizations in order to establish a reliable biomarker signature of diabetes mellitus. Differential expression patterns of crucial contractile proteins agree with the concept of impaired muscle strength in diabetes (16-19). The pattern of altered abundance in contractile and regulatory elements does not indicate a fibre type-specific shift. On the one hand, protein spots representing myosin heavy chain 4 and troponin $\mathrm{C}$ were decreased in GK muscle. On the other hand, crucial contractile elements such as slow and fast isoforms of myosin light chain, myozenin and fast troponin $\mathrm{T}$ were found to be increased in diabetic preparations. Thus, in agreement with previous studies that have shown marked pathophysiological alterations in GK rat tissues (5,7,30-38) and diabetic specimens from patients $(2-4,6,15-18)$, the results presented here confirm the drastic effects of type-2 diabetes on voluntary contractile fibres.

In the field of neuromuscular pathology, there is an urgent need for the establishment of disease-specific biomarker signatures that can be used to differentiate between common changes due to general fibre degeneration versus pathobiochemical mechanisms that are unique to a particular muscular disorder. Various proteomic profiling programmes have been initiated to identify novel signature molecules of muscular atrophy, muscular dystrophy, muscle transformation and age-related muscle wasting (57). In our experience, it is advisable to initially carry out small-scale pilot experiments to determine the general suitability of different protein dyes for specific proteomic applications. Thus, besides taking into account differing electrophoretic mobilities of soluble versus integral proteins, it is also important to keep in mind the affinity of diverse classes of proteins for different dye staining protocols. Here, we have shown that the DIGE method and the fluorescent dye RuBPs are highly suitable to determine protein alterations in the non-obese diabetic GK gastrocnemius muscle. In conclusion, the proteomic identification of the biomarker signature of diabetic effects on skeletal muscle may be useful for complementing future physiological and biochemical investigations into the molecular mechanisms of peripheral insulin resistance (58). The newly established tissue-specific combination of disease markers might also be exploitable in the evaluation of the effects of novel drug regimes, gene therapy approaches or cell-based therapies for counter-acting serious side effects of type- 2 diabetes in peripheral tissues.

\section{Acknowledgements}

Research was supported by a Hume Scholarship from NUI Maynooth, a project grant from the Irish Health Research Board (HRB-RP/2005/3) and an equipment grant from the Higher Education Authority (HEA-RERGS-07-NUIM).

\section{References}

1. Sundsten $\mathrm{T}$ and Ortsater H: Proteomics in diabetes research. Mol Cell Endocrinol 297: 93-103, 2009.

2. Hojlund K, Wrzesinski K, Larsen PM, Fey SJ, Roepstorff P, Handberg A, Dela F, Vinten J, McCormack JG, Reynet C and Beck-Nielsen H: Proteome analysis reveals phosphorylation of ATP synthase beta-subunit in human skeletal muscle and proteins with potential roles in type 2 diabetes. J Biol Chem 278: 10436-10442, 2003.

3. Stentz FB and Kitabchi AE: Transcriptome and proteome expressions involved in insulin resistance in muscle and activated T-lymphocytes of patients with type 2 diabetes. Genomics Proteomics Bioinformatics 5: 216-235, 2007. 
4. Hwang H, Bowen BP, Lefort N, Flynn CR, De Filippis EA Roberts C, Smoke CC, Meyer C, Hojlund K, Yi Z and Mandarino LJ: Proteomics analysis of human skeletal muscle reveals novel abnormalities in obesity and type 2 diabetes mellitus. Diabetes 59: 33-42, 2010.

5. Mullen E and Ohlendieck K: Proteomic profiling of non-obese type 2 diabetic skeletal muscle. Int J Mol Med 25: 445-458, 2010

6. Lefort N, Glancy B, Bowen B, Willis WT, Bailowitz Z, De Filippis EA, Brophy C, Meyer C, Hojlund K, Yi Z and Mandarino LJ: Increased reactive oxygen species production and lower abundance of complex I subunits and carnitine palmitoyltransferase $1 \mathrm{~B}$ protein despite normal mitochondrial respiration in insulin-resistant human skeletal muscle. Diabetes 59: 2444-2452, 2010.

7. Mullen E and Ohlendieck K: Proteomic analysis of the mitochondria-enriched fraction from diabetic rat skeletal muscle. J Integ Omics: Nov 9, 2010 (E-pub ahead of print).

8. Petersen KF and Shulman GI: Pathogenesis of skeletal muscle insulin resistance in type 2 diabetes mellitus. Am J Cardiol 90: $11 \mathrm{G}-18 \mathrm{G}, 2002$.

9. Phielix E and Mensink M: Type 2 diabetes mellitus and skeletal muscle metabolic function. Physiol Behav 94: 252-258, 2008

10. Abdul-Ghani MA and DeFronzo RA: Pathogenesis of insulin resistance in skeletal muscle. J Biomed Biotech 2010: 476279, 2010.

11. Scheen AJ: Pathophysiology of type 2 diabetes. Acta Clin Belg 58: 335-341, 2003.

12. Sander GE and Giles TD: Diabetes mellitus and heart failure. Am Heart Hosp J 1: 273-280, 2003.

13. Tusie-Luna MT: Genes and type 2 diabetes mellitus. Arch Med Res 36: 210-222, 2005.

14. King H, Aubert RE and Herman WH: Global burden of diabetes, 1995-2025: prevalence, numerical estimates, and projections. Diabetes Care 21: 1414-1431, 1998.

15. Wild S, Roglic G, Green A, Sicree R, and King H: Global prevalence of diabetes: estimates for the year 2000 and projections for 2030. Diabetes Care 27: 1047-1053, 2004.

16. Gregg EW, Beckles GL, Williamson DF, Leveille SG, Langlois JA, Engelgau MM and Narayan KM: Diabetes and physical disability among US adults. Diabetes Care 23 1272-1277, 2000.

17. Andersen H, Nielsen S, Mogensen CE and Jakobsen J: Muscle strength in type 2 diabetes. Diabetes 53: 1543-1548, 2004.

18. Park SW, Goodpaster BH, Strotmeyer ES, De Rekeneire N Harris TB, Schwartz AV, Tylavsky FA and Newman AB: Decreased muscle strength and quality in older adults with type 2 diabetes. Diabetes 55: 1813-1818, 2006.

19. Park SW, Goodpaster BH, Lee JS, Kuller LH, Boudreau R, De Rekeneire N, Harris TB, Kritchevsky S, Tylavsky FA, Nevitt M, Cho YW and Newman AB: Health, aging, and body composition study: excessive loss of skeletal muscle mass in older adults with type 2 diabetes. Diabetes Care 32: 1993-1997, 2009.

20. Mulvey C, Mullen E and Ohlendieck E: The pathobiochemical role of the dystrophin-dystroglycan complex and the $\mathrm{Ca}^{2+}$ handling apparatus in diabetes-related muscle weakness (Review) Mol Med Rep 1: 297-306, 2008.

21. Issaq $\mathrm{H}$ and Veenstra T: Two-dimensional polyacrylamide gel electrophoresis (2D-PAGE): advances and perspectives. Biotechniques 44: 697-700, 2008.

22. Weiss W and Gorg A: High-resolution two-dimensional electrophoresis. Methods Mol Biol 564: 13-32, 2009.

23. Westermeier R and Schickle H: The current state of the art in high-resolution two-dimensional electrophoresis. Arch Physio Biochem 115: 279-285, 2009.

24. Gorg A, Weiss W and Dunn MJ: Current two-dimensional electrophoresis technology for proteomics. Proteomics 4: 3665-3685, 2004

25. Wittmann-Liebold B, Graack HR and Pohl T: Two-dimensional gel electrophoresis as tool for proteomics studies in combination with protein identification by mass spectrometry. Proteomics 6 : 4688-4703, 2006.

26. Rabilloud T, Vaezzadeh AR, Potier N, Lelong C, Leize-Wagner E and Chevallet M: Power and limitations of electrophoretic separations in proteomics strategies. Mass Spectrom Rev 28: 816-843, 2009

27. Domon B and Aebersold R: Mass spectrometry and protein analysis. Science 312: 212-217, 2006.

28. Canas B, Lopez-Ferrer D, Ramos-Fernandez A, Camafeita E and Calvo E: Mass spectrometry technologies for proteomics. Brief Funct Genomic Proteomic 4: 295-320, 2006.
29. Kitahara A, Toyota T, Kakizaki M and Goto Y: Activities of hepatic enzymes in spontaneous diabetes rats produced by selective breeding of normal Wistar rats. Tohoku J Exp Med 126: 7-11, 1978.

30. Abdel-Halim SM, Guenifi A, Luthman H, Grill V, Efendic S and Ostenson CG: Impact of diabetic inheritance on glucose tolerance and insulin secretion in spontaneously diabetic GK-Wistar rats Diabetes 43: 281-288, 1994

31. Portha B, Serradas P, Bailbe D, Suzuki K, Goto Y and Giroix MH: Beta-cell insensitivity to glucose in the GK rat, a spontaneous nonobese model for type II diabetes. Diabetes 40: 486-491, 1991

32. Witte K, Jacke K, Stahrenberg R, Arlt G, Reitenbach I, Schilling L and Lemmer B: Dysfunction of soluble guanylyl cyclase in aorta and kidney of Goto-Kakizaki rats: influence of age and diabetic state. Nitric Oxide 6: 85-95, 2002.

33. Krook A, Kawano Y, Song XM, Efendic S, Roth RA, WallbergHenriksson $\mathrm{H}$ and Zierath JR: Improved glucose tolerance restores insulin-stimulated Akt kinase activity and glucose transport in skeletal muscle from diabetic Goto-Kakizaki rats. Diabetes 46: 2110-2114, 1997.

34. Dadke SS, Li HC, Kusari AB, Begum N and Kusari J: Elevated expression and activity of protein-tyrosine phosphatase 1B in skeletal muscle of insulin-resistant type II diabetic GotoKakizaki rats. Biochem Biophys Res Comm 274: 583-589, 2000.

35. Yasuda K, Nishikawa W, Iwanaka N, Nakamura E, Seino Y, Tsuda $\mathrm{K}$ and Ishihara A: Abnormality in fibre type distribution of soleus and plantaris muscles in non-obese diabetic GotoKakizaki rats. Clin Exp Pharmacol Physiol 29: 1001-1008, 2002.

36. Steiler TL, Galuska D, Leng Y, Chibalin AV, Gilbert M and Zierath JR: Effect of hyperglycemia on signal transduction in skeletal muscle from diabetic Goto-Kakizaki rats. Endocrinology 44: 5259-5267, 2003.

37. Mulvey C, Harno E, Keenan A and Ohlendieck K: Expression of the skeletal muscle dystrophin-dystroglycan complex and syntrophin-nitric oxide synthase complex is severely affected in the type 2 diabetic Goto-Kakizaki rat. Eur J Cell Biol 84 $867-883,2005$

38. Shen W, Hao J, Tian C, Ren J, Yang L, Li X, Luo C, Cotma CW and Liu J: A combination of nutriments improves mitochondrial biogenesis and function in skeletal muscle of type 2 diabetic goto-kakizaki rats. PLoS One 3, e2328, 2008.

39. Nishimura RN and Sharp FR: Heat shock proteins and neuromuscular disease. Muscle \& Nerve 32: 693-709, 2005.

40. Golenhofen N, Perng MD, Quinlan RA and Drenckhahn D: Comparison of the small heat shock proteins alphaB-crystallin, MKBP, HSP25, HSP20, and cvHSP in heart and skeletal muscle. Histochem Cell Biol 122: 415-425, 2004.

41. Nicholl ID and Quinlan RA: Chaperone activity of alphacrystallins modulates intermediate filament assembly. EMBO J 13: 945-953, 1994.

42. Van Montfort R, Slingsby C and Vierling E: Structure and function of the small heat shock protein/alpha-crystallin family of molecular chaperones. Adv Protein Chem 59: 105-156, 2001.

43. Bradford MM: A rapid and sensitive method for the quantitation of microgram quantities of protein utilizing the principle of protein-dye binding. Anal Biochem 72: 248-254, 1976

44. Donoghue P, Doran P, Wynne K, Pedersen K, Dunn MJ and Ohlendieck K: Proteomic profiling of chronic low-frequency stimulated fast muscle. Proteomics 7: 3417-3430, 2007.

45. Doran P, Martin G, Dowling P, Jockusch H and Ohlendieck K Proteome analysis of the dystrophin-deficient MDX diaphragm reveals a drastic increase in the heat shock protein cvHSP Proteomics 6: 4610-4621, 2006.

46. Doran P, O'Connell K, Gannon J, Kavanagh M and Ohlendieck K: Opposite pathobiochemical fate of pyruvate kinase and adenylate kinase in aged rat skeletal muscle as revealed by proteomic DIGE analysis. Proteomics 8: 364-377, 2008

47. Karp NA and Lilley KS: Maximising sensitivity for detecting changes in protein expression: experimental design using minimal CyDyes. Proteomics 5: 3105-3115, 2005.

48. Rabilloud T, Strub JM, Luche S, van Dorsselaer A and Lunardi J: A comparison between Sypro Ruby and ruthenium II tris (bathophenanthroline disulfonate) as fluorescent stains for protein detection in gels. Proteomics 1: 699-704, 2001.

49. Gannon J, Staunton L, O'Connell K, Doran P and Ohlendieck K Phosphoproteomic analysis of aged skeletal muscle. Int J Mol Med 22: 33-42, 2008. 
50. Staples GO, Bowman MJ, Costello CE, Hitchcock AM, Lau JM, Leymarie N, Miller C, Naimy H, Shi X and Zaia J: A chipbased amide-HILIC LC/MS platform for glycosaminoglycan glycomics profiling. Proteomics 9: 686-695, 2009.

51. Tonge R, Shaw J, Middleton B, Rowlinson R, Rayner S, Young J, Pognan F, Hawkins E, Currie I and Davison M: Validation and development of fluorescence two-dimensional differential gel electrophoresis proteomics technology. Proteomics 1: 377-396, 2001.

52. Marouga R, David S and Hawkins E: The development of the DIGE system: 2D fluorescence difference gel analysis technology. Anal Bioanal Chem 382: 669-678, 2005.

53. Viswanathan S, Unlu $M$ and Minden JS: Two-dimensional difference gel electrophoresis. Nat Protoc 1: 1351-1358, 2006.
54. Doran P, Gannon J, O'Connell K and Ohlendieck K: Proteomic profiling of animal models mimicking skeletal muscle disorders. Proteomics Clin Appl 1: 1169-1184, 2007.

55. Miao L and St Clair DK: Regulation of superoxide dismutase genes: implications in disease. Free Radic Biol Med 47: 344-356, 2009.

56. Doran P, Gannon J, O'Connell K and Ohlendieck K: Aging skeletal muscle shows a drastic increase in the small heat shock proteins $\alpha$ B-crystallin/HspB5 and cvHsp/HspB7. Eur J Cell Biol 86: 629-640, 2007.

57. Ohlendieck K: Proteomics of skeletal muscle differentiation, neuromuscular disorders and fiber aging. Expert Rev Proteomics 7: 283-296, 2010.

58. Korc M: Diabetes mellitus in the era of proteomics. Mol Cell Proteomics 2: 399-404, 2003. 